\title{
IDENTIFYING DROUGHT TOLERANT WHEAT VARIETIES USING DIFFERENT INDICES
}

\author{
R.P. Meena, S.C. Tripathi, S. Chander, R.S. Chookar, Msamrutha \\ A. Verma and R.K. Sharma* \\ Indian Institute of Wheat \& Barley Research, Karnal-132001, India
}

\begin{abstract}
Moisture stress is a major constraint in productivity across the wheat growing zones of India. Climate change and uneven rainfall further aggravate the situation under moisture stress environments. Wheat genotypes capable of giving increased yield under a broad range of optimal and sub-optimal water availability are considered desirable. This study was undertaken to evaluate various selection indices of moisture stress and their applicability in identifying drought tolerant wheat genotypes which can adapt to various moisture stressed environments in different wheat growing zones of India i.e., North Western Plain Zone, North Eastern Plain Zone, Central Zone and Peninsular Zone. A set of wheat genotypes were tested under moisture stress condition of different irrigation regimes. Irrigation treatments were arranged as main plots and varieties as sub plots. Fifteen wheat varieties representing major wheat growing zones of India were tested for water stress tolerance during two consecutive years. It was found that yield under irrigated conditions $\left(\mathrm{Y}_{\mathrm{pi}}\right)$, yield under stress conditions $\left(\mathrm{Y}_{\mathrm{si}}\right)$ and lower stress tolerance index (STI), were marked indices for stress tolerance. Significantly positive correlation of $Y_{\mathrm{pi}}$ and $\mathrm{Y}_{\mathrm{si}}$ with STI, mean productivity (MP), geometric mean productivity (GMP) were obtained during both the years of the study. The indices of STI, MP and GMP could be used as the desirable indices for screening drought tolerant varieties. On the basis of findings of these indices wheat varieties $\mathrm{NI}-5439, \mathrm{WH}-1021$ and HD-2733 were found having higher stress tolerance and with better yield potential under both normal and restricted irrigation conditions of India.
\end{abstract}

Keywords: Genotype variation, Grain yield, Moisture stress indices, Wheat

* Corresponding author email: adityarajjaipur@gmail.com

Received: 14.01.2015 


\section{INTRODUCTION}

Water scarcity in arid and semi-arid regions is a major concern for agricultural authorities around the world (Sharafi et al., 2011). Water stress is heterogeneous, both in time and space and highly unpredictable in nature. Undulated topography leads to uneven distribution of rainfall or irrigation water which leads to within field spatial variability owing to excess water at lower elevations and in-adequate availability of water at higher elevations (Naresh et al., 2004). The ability of wheat varieties to perform fairly well under variable water stress is an important trait for production stability under water stress conditions (Pirayvatlou, 2001). Several drought stress indices, such as stress tolerance (TOL) (Rosielle and Hamblin 1989), mean productivity (MP) (Mc Caig and Clarke, 1982), geometric mean productivity (GMP) (Ramirez and Kelly, 1998), stress susceptibility index (SSI) (Fischer and Maurer, 1978), stress tolerance index (STI) (Fernandez, G.C.J. 1992), have been suggested to identify varieties with better stress tolerance. Significant and positive correlation of $\mathrm{Y}_{\mathrm{pi}}$ (yield under irrigated conditions) with MP, GMP and STI have been reported. These indices are efficient in identifying high yielding cultivars under moisture stress conditions (Talebi et. al., 2009) and are identified as reliable criteria to select varieties for terminal drought stress condition. Huang (2000) established mathematical relationship between stress tolerance (TOL) and stress indices (MP, SSI, GMP and STI) under various water stress regimes. It has been suggested that a larger value of TOL and SSI show relatively more sensitivity to stress, therefore, a smaller values of TOL and SSI should be favoured while selecting stress tolerant varieties (Huang, 2000). Fischer and Maurer (1978) explained that varieties with an SSI of less than a unit are drought resistant, since their yield reduction under drought condition is smaller than mean yield reduction of other varieties. Correlation coefficients of grain yield with GMP and STI in both environmental conditions were found significantly positive by Azizi et al. (2009). The present study was undertaken with the objective to compare and evaluate various selection indices of moisture stress tolerance and to identify the high yielding wheat varieties having higher ability to tolerate drought stress conditions than that of normal conditions.

\section{MATERIALS AND METHODS}

An experiment was conducted for two consecutive rabi seasons (2010-11 and 2011-12) at research farm of Directorate of Wheat Research, Karnal, Haryana, India. The agro-climate of the location is characterized by sub tropical and semi arid conditions with hot dry summer (March-June), wet monsoon season (July-October) and cool dry winters (November-February). Average annual rainfall of $744 \mathrm{~mm}$, of which about 80 percent is received during the monsoon. The mean maximum temperature ranges between $34-39^{\circ} \mathrm{C}$ in summer and mean minimum temperature ranging between $6-7^{\circ} \mathrm{C}$ in winter. 
The crop season received $129.7 \mathrm{~mm}$ and $36.3 \mathrm{~mm}$ rainfall during 2010-11 and 2011-12, respectively. The soil texture of experimental field was sandy clay loam with $\mathrm{pH} 7.3\left(1: 2.5\right.$ soils to water) and EC $2.0 \mathrm{ds} \mathrm{m}^{-1}$. The soil was having organic carbon $0.42 \%$, available $\mathrm{N} 190 \mathrm{~kg} \mathrm{ha}^{-1}$, available P $17.8 \mathrm{~kg} \mathrm{ha}^{-1}$ and available K 165 $\mathrm{kg} \mathrm{ha}^{-1}$ at beginning of the experiment. Existing cropping pattern is rice-wheat rotation. The experiment was conducted in split plot design with three replications. Sowing of trial was done on 10th and 13th November in 2010 and 2011, respectively. Different irrigation levels i.e., normal and restricted irrigations were arranged in main plot, while varieties were randomized in sub plots. Under normal irrigation treatment five irrigations were provided as per standard recommendations (crown root initiation stage, late tillering stage, late jointing stage, flowering stage, and dough stage). Under restricted irrigation treatment only two irrigations, first at crown root initiation stage (21-25 DAS) and second at boot leaf stage (80-85 DAS), were given. Fifteen varieties (PBW-343, UP- 2425, UP- 2338, WH- 1021, PBW- 373, DBW- 16, RAJ3765, DBW- 17, HUW- 234, DBW- 14, K- 9107, HD- 2733, GW- 322, WH- 147, and NI- 5439) were chosen from four major wheat growing zones of India (North West Plain Zone, North Eastern Plain Zone, from Central Zone and Peninsular Zone) to evaluate for stress tolerance. Genotype RAJ- 3765 is drought and heat tolerant and used as check for drought and heat tolerant screening nurseries whereas, genotype K9107 is a released variety for rainfed conditions. Rests of the genotypes are recommended varieties for irrigated conditions (Anonymous, 2013). The rows of 8-m length were spaced 20- $\mathrm{cm}$ apart. Recommended dose of fertilizers (150:60:40 kg $\mathrm{N}: \mathrm{P}_{2} \mathrm{O}_{5}: \mathrm{K}_{2} \mathrm{O}$ ha $^{-1}$ ) were applied. Full dose of phosphorus and potash and $1 / 2$ dose of nitrogen were applied as basal and remaining 1/2 nitrogen was applied with second irrigation. For weed control, one spray of sulfosulfuron (Leader 75 WG) @ $25 \mathrm{~g} \mathrm{ha}^{-1}$ was applied 10 days after first irrigation. Subsequently one weeding was done manually for controlling of the weeds left after herbicide spray.

Data were recorded for different parameters according to standard procedures. The observation on number of effective tillers per square meter was recorded from the centre of plot in each plot at maturity. Chlorophyll content was measured by chlorophyll meter at physiological maturity stage of the crop. Yield was taken from $9.8 \mathrm{~m}^{2}$ plot (7.0 m length and $1.4 \mathrm{~m}$ width). Grain samples were randomly taken from each sub plot and 1000 grains were counted with Contador seed counter and weighed. Different stress tolerance indices namely, SSI, STI, MP, TOL and GMP were calculated as per the formula mentioned below:

$\mathrm{SI}($ stress intensity $)=\left[1-\left(\mathrm{Y}_{\mathrm{si}} / \mathrm{Y}_{\mathrm{pi}}\right)\right] \quad$ (1) $\quad$ (Fischer and Maurer, 1978)

Where, $\mathrm{Y}_{\mathrm{si}}=$ Total mean (overall mean across genotypes) yield under stress condition;

$\mathrm{Y}_{\mathrm{pi}}=$ Total mean (overall mean across genotypes) yield under normal condition

SSI (stress susceptibility index $)=\left[1-\left(\mathrm{Y}_{\mathrm{si}} / \mathrm{Y}_{\mathrm{pi}}\right)\right] / \mathrm{SI}$ (2) (Fischer and Maurer, 1978) 
Where, $\mathrm{Y}_{\mathrm{si}}=$ yield of genotype under stress conditions; $\mathrm{Y}_{\mathrm{pi}}=$ yield of genotype under normal condition

STI $($ stress tolerance index $)=\left(\mathrm{Y}_{\mathrm{pi}} * \mathrm{Y}_{\mathrm{si}}\right) / \mathrm{Y}_{\mathrm{p} 2}$ (3) (Fernandez, G.C.J. 1992)

MP $($ mean productivity $)=\left(\mathrm{Y}_{\mathrm{pi}}+\mathrm{Y}_{\mathrm{si}}\right) / 2 \quad$ (4) $(\mathrm{Mc}$ Caig and Clarke, 1982)

TOL $($ stress tolerance $)=\mathrm{Y}_{\mathrm{pi}} \mathrm{Y}_{\mathrm{si}} \quad$ (5) (Rosielle and Hamblin, 1981)

GMP (geometric mean productivity) $=\sqrt{ } \mathrm{Y}_{\mathrm{s}} * \mathrm{Y}_{\mathrm{p}} \quad$ (6) (Ramirez and Kelly, 1998)

Statistical calculations including combined analysis and calculation of quantitative index of drought sensitivity and simple correlation was done by SAS software (Version 9.2).

\section{RESULTS AND DISCUSSION}

Results revealed that there was considerable variability among varieties for water stress tolerance under both water stressed and normal moisture conditions. The ANOVA showed significant difference for yield under non-stress (Ypi) and stress (Ysi) conditions and all drought tolerant indices (Table 1), which indicates that genotypes are differing for stress tolerance.

Stress Intensity: The overall stress intensity during year 2010-11 was 0.24 reflecting that yield reduction in 2010-11 was about one-fourth under stress conditions in comparison to yield under well irrigated conditions. The first year of experimentation (2010-11) received fairly good amount of rainfall, therefore, stress intensity remained low (0.24) which resulted in less reduction in yield under stress conditions. Whereas in second year rainfall received was negligible, hence, stress intensity was 0.54 which reflects that there was more than fifty percent yield reduction under stress conditions as compared to that of yield under non stress conditions. The stress intensity index can take value between 0 and 1 . The larger value of stress intensity (SI) can indicates more severe stress conditions (Dejan et al., 2008). Mean sum of squares of over the year analysis is presented in Table 1. Year as well as genotype effect was significant $(\mathrm{P}=0.05)$ for all the parameters except SSI. Pooled interaction study for grain yield showed that genotype $\mathrm{x}$ year, genotype $\mathrm{x}$ moisture level and genotype $\mathrm{x}$ moisture level $\mathrm{x}$ year was not significant. Whereas, moisture level $\mathrm{x}$ year interaction for grain yield was significant due to differential rainfall pattern between two seasons. Talebi et al. (2009) observed significant difference among stress conditions for grain yield and suggested that high yield potential under normal conditions does not necessarily results in improved yield under stress conditions. Hence indirect selection of genotypes for moisture stress conditions based on the results of normal moisture conditions will not be efficient. These findings are in agreement with Sio-Se Mardeh et al. (2006).

Yearly and combined analyses over the years of various stress tolerant indices have been mentioned in Table 2. Mean yield of genotypes under normal conditions 
( $\left.\mathrm{Y}_{\mathrm{Pi}}\right)$ ranged from $48.6 \mathrm{t} \mathrm{ha}^{-1}$ (HUW- 234) to $61.4 \mathrm{t} \mathrm{ha}^{-1}$ (NI- 5439). Yield of genotypes under stress conditions (YSi) varied from $29.4 \mathrm{t} \mathrm{ha}^{-1}$ (DBW-14) to $40.9 \mathrm{t}$ $\mathrm{ha}^{-1}$ (WH-147). Based on pooled analysis, it was found that genotype NI-5439 had recorded highest yield (61.4 and $\left.40.9 \mathrm{t} \mathrm{ha}^{-1}\right)$ under normal $\left(\mathrm{Y}_{\mathrm{pi}}\right)$ and stress $\left(\mathrm{Y}_{\mathrm{si}}\right)$ conditions, respectively. Therefore, it is suggested that NI-5439 is a stress tolerant genotype with high yielding ability.

Stress Tolerance (TOL): A larger value of TOL show more sensitivity to stress, thus a smaller value of TOL is favored. The lowest TOL values were recorded for varieties HUW- 234 (17.6), DBW- 16 (17.6) and UP -2425 (17.8). The higher TOL values were obtained in variety GW- 322 (24.7), K- 9107 (23.5) and WH- 147 (23.2) (Table 2). Larger the TOL value, larger the yield loss under stress conditions and higher sensitivity to drought. Selection of genotypes based on TOL favours genotypes with low yield potential and higher yield under stress conditions (Zangi, 1998). HUW-234, DBW-16, UP-2425, UP-2338 and NI-5439 genotypes were the smallest TOL, so were the best cultivars based on this index. Similar observations were recorded by other workers (Anonymous, 2013).

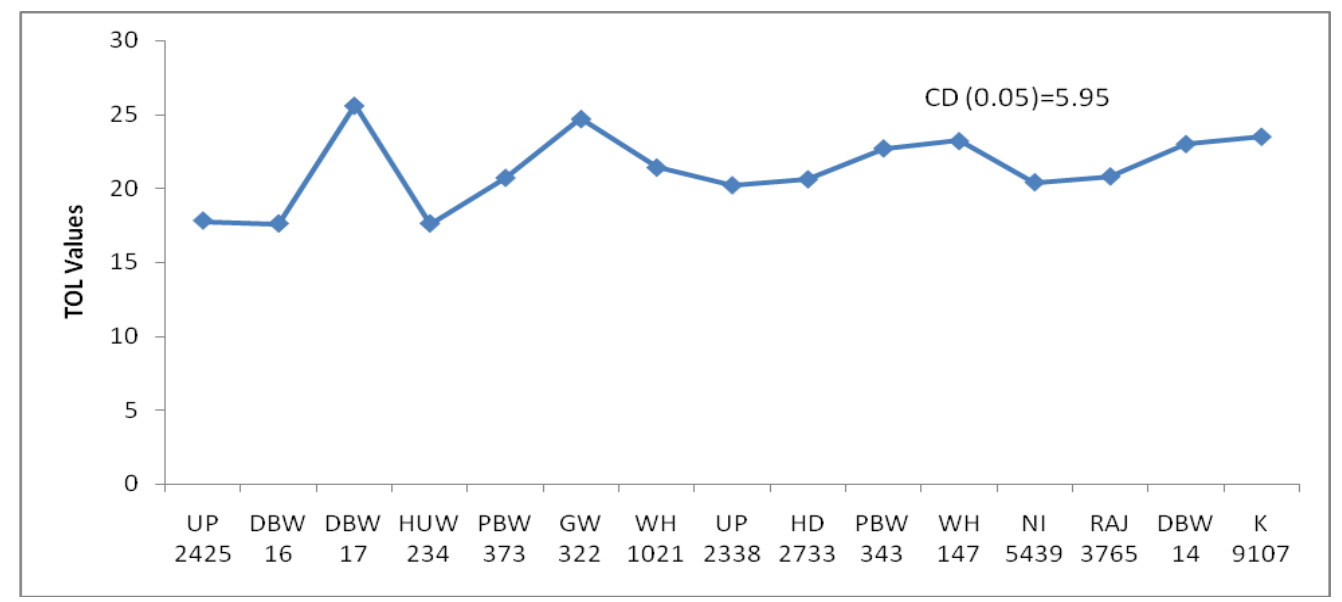

Stress Tolerance Index (STI): The higher STI values caused higher stress tolerance and yield potential (Rajmani, 1994 and Rosielle and Hamblin, 1989). The highest values of STI was obtained for genotypes NI-5439 (0.81), Raj-3765 (0.67), PBW-343 (0.66), WH-147 (0.66) and HD-2733 (0.65) and so were selected by this index (Table 2). Generally, STI and GMP help in identification of genotype which yields well under both stress and non stress condition. 


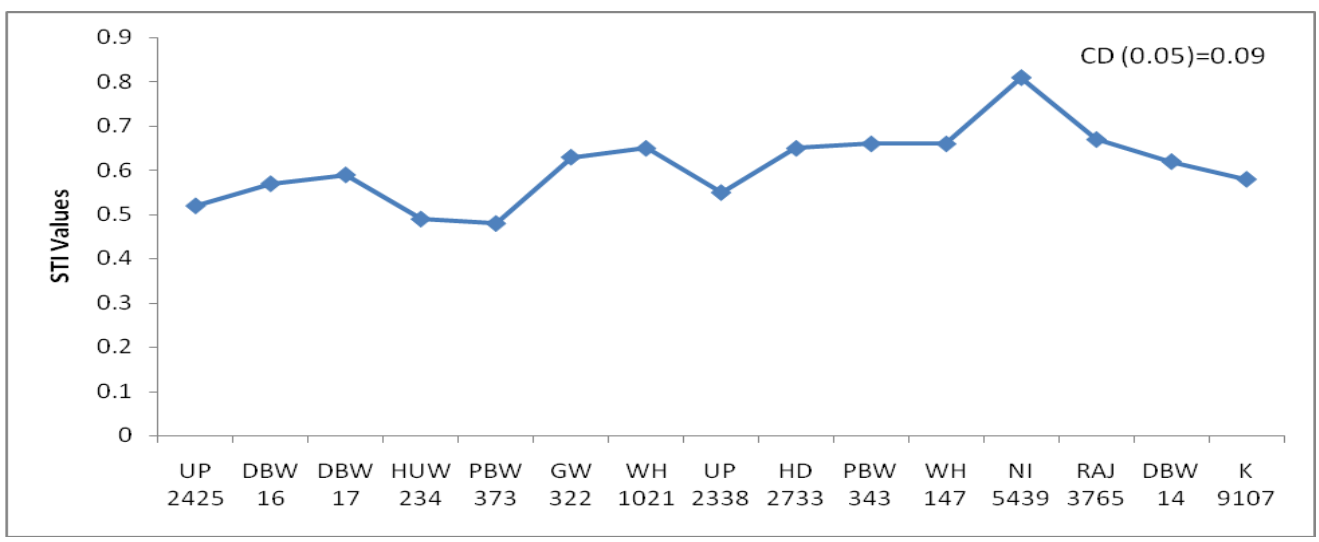

Stress Susceptibility Index (SSI): The smaller SSI caused the greater stress tolerance (Zangi, 1998). Stress tolerance (TOL) and SSI are positively correlated $(\mathrm{r}=0.95, \mathrm{p}<0.001)$. The genotypes NI- 5439 had the smallest SSI index $(0.78)$ followed by HD-2733 (0.92), UP-2425 (0.92) and HUW-234 (0.92) so these were the selected genotypes by this index (Table 2 ). This observation corroborated the finding of other workers who explained that varieties with an SSI of less than 1 unit are drought resistant (Ramirez \& Kelly, 1998). The stress susceptibility index helps in identifying the genotype, which has less reduction in grain yield under stress conditions compared to normal condition.

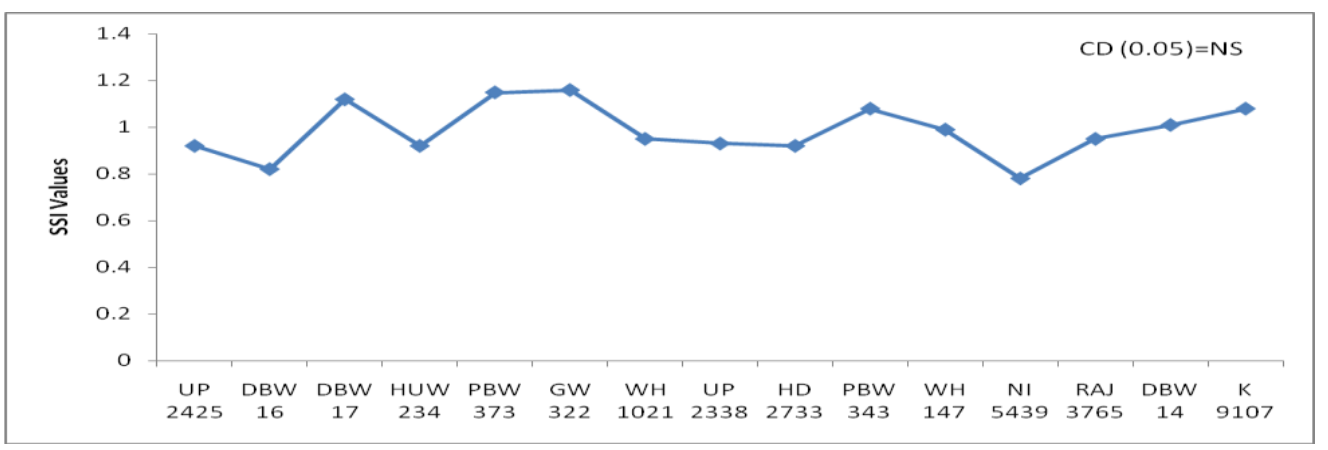

Mean Productivity (MP): Mean Productivity favours higher yield potential and lower stress tolerance (Zangi, 1998). Therefore, selection based on MP may not be providing genotypes with increased yield in stress conditions. Value for NI-5439 was the highest (51.1) and significantly more than all other varieties followed by variety WH-147 (46.8) and Raj-3765 (46.6) (Table 2). Hence, these were the best genotypes based on this index. MP is based on the arithmetic means and therefore, it may have an upward bias due to a relatively larger difference between Ypi and Ysi (Zangi, 2005). 


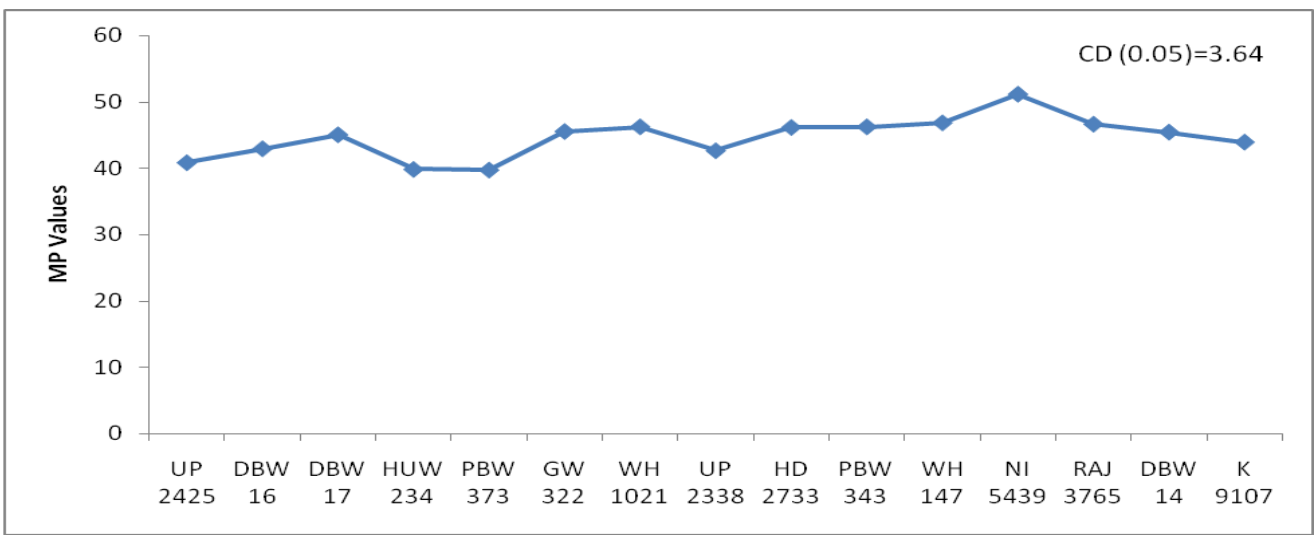

Generally higher MP value is indicator of genotypes with higher yield potential. Whereas the geometric mean (GMP) is less sensitive to extreme values (Rajmani, 1994). GMP values recorded were highest in variety NI-5439 (49.6) followed by Raj3765 (45.1). NI-5439 also showed significantly higher GMP compared to all other varieties. Though, the indices are mathematical expression of same variables, yet their relations with the yield are different under non stress and stress environment (Amini et al., 2012).

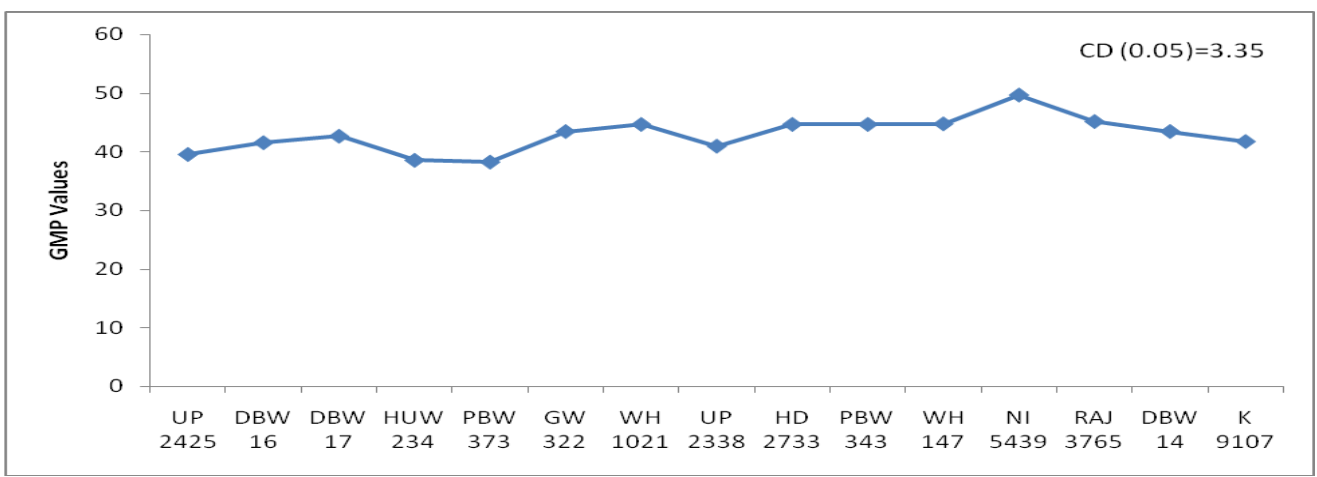

During 2011-12, the rainfall was negligible; therefore, it can be considered a season of severe stress and indicator of tolerance to moisture stress. In this year the STI was highest for NI- 5439 (0.67) followed by WH-1021 (0.55) and HD- 2733 (0.54). These three varieties (NI- 5439, WH- 1021 and HD-2733) were the highest yielders (29.9, 27.2 and $26.8 \mathrm{t} \mathrm{ha}^{-1}$, respectively) under stress conditions. Interestingly, same three varieties ranked highest in terms of GMP (43.0, 38.8 and 38.4) in the same order. Mean productivity (MP) also remained the highest for NI- 5439 (45.9) followed by WH-1021 (41.3). HD- 2733 and DBW- 17 ranked third with MP value of 40.9. As far as TOL value is concerned although NI- 5439 produced highest yield under stress, 
the TOL value was high for this genotype. Similarly, this anomaly was observed in case of WH-1021and HD-2733 which yielded higher than other genotypes but their TOL value was also high. This suggests that TOL value cannot be taken as a good indicator of stress tolerance.

Significantly positive correlation of Ypi and Ysi $(\mathrm{r}=0.64, \mathrm{p}<0.05)$, Ypi and STI (0.89 \& 0.88, p<0.001), Ysi and STI (0.92 \& 0.93, p<0.001), Ypi and MP (0.91 \& $0.95, \mathrm{p}<0.001)$ Ysi and MP $(0.91 \& 0.84, \mathrm{p}<0.001)$, Ypi and GMP $(0.89 \& 0.88$, $\mathrm{p}<0.001)$ and Ysi and GMP $(0.93 \& 0.92, \mathrm{p}<0.001)$ were obtained during both the years of study (Table 3$)$. Positive correlation of STI with MP $(0.99 \& 0.98, p<0.001)$, STI and GMP (0.99 \& 0.99, p<0.001), and that of MP with GMP (0.99 \& 0.98, $\mathrm{p}<0.001$ ) were observed (Table 3 ). On the basis of these results, the drought tolerance indices, STI, SSI, MP and GMP may be used for screening drought tolerance varieties. All stress indices used in the study indicated that genotypes NI-5439, Raj3765, HD-2733, WH-147, UP-2425 and HUW-234perform better in terms of yield under moisture stress conditions. Number of effective tillers, 1000 grain weight and rate of chlorophyll disappearance (speed of senescence) played an important role in sustaining the effective yield under stress conditions. Application of stress condition reduced the tillers $/ \mathrm{m}^{2}$, chlorophyll content and thousand grain weight by $19.6,23.5$ and 4.3 percent respectively (Table 4). Though, varieties responded differently in above mentioned three parameters, reduction in tillers $/ \mathrm{m}^{2}$, chlorophyll content at physiological maturity and thousand grain weight (TGW) among varieties ranges 10 to 31,9 to 25 and 0 to $14 \%$, respectively under normal and stress moisture condition. Lowest reduction in tillers $/ \mathrm{m}^{2}$, chlorophyll content at physiological maturity and thousand grain weight was in Raj 3765 and DBW- 14 (14.0\%), Raj 3765 and NI$5439(20 \%)$ and PBW- $373(0 \%)$ respectively. The varieties which were able to produce reasonable yield under water stress conditions showed less fluctuations in contrasting conditions and produced comparatively higher number of effective tillers, maintained higher grain weight (TGW) and lost chlorophyll content comparatively at slower rate during senescence stage.

On the basis of this study, it can be concluded that along with SI, the use of stress indices follows the order of STI, SSI, MP and GMP for selection of drought tolerant genotypes under stress conditions and they may be used to screen wheat varieties tolerant to moisture stress conditions. Conclusions of this study corroborate earlier findings of Shen et al., 2011. It is further concluded that among the tested genotypes, NI-5439, Raj-3765, WH-147 and HD-2733 are the superior wheat genotypes with higher stress resistance and comparatively better yield potential under both irrigated and stress conditions. 


\section{REFERENCES}

Amini, A.R., Ali, S. and Mohamad, H.S. 2012. Assess the usefulness of various indices and yield potential in identifying of barley adapted to water stress. International Journal of Agriculture and Crop Sciences, 47:364-367

Anonymous. 2013. Progress Report of the All India Coordinated Wheat \& Barley Improvement Project 2012-13 Vol. 1 pp. 252

Azizi, C.S., Mostafaei, H., Imanparast, L. and Eivazian, M.R. 2009. Evaluation of drought tolerance in lentil advanced varieties in Ardabil region, Iran. Journal of Food, Agriculture and Environment, 7(3\&4): 283-288

Dejan, D. Miroslav, Z., Desimier, K., Stephen, R. K., and Gordana, S.M. 2008. Genotype x environment interaction for wheat yield in different drought stress conditions and agronomic traits suitable for selection. Australian Journal of Agricultural Research, 59: 536-545

Fernandez, G.C.J. 1992. Effective selection criteria for assessing plant stress tolerance. In: Kuo C.G. (Ed.), Proceedings of the International Symposium on Adaptation of Vegetables and Other Food Crops in Temperature and Water Stress, Publication, Tainan, Taiwan.

Fischer, R.A. and Maurer, R. 1978. Drought resistance in spring wheat cultivars. Australian Journal of Agricultural Research, 29:897-912

Huang, B. 2000. Role of root morphological and physiological characteristics in drought resistance of plants. In: Wilkinson, R. E. (ed.). Plant-Environment Interactions. Marcel Dekker Inc., New York, pp. 39-64

McCaig, T.N. and Clarke, J. M. 1982. Seasonal changes in nonstructural carbohydrate levels of wheat and oats grown in semiarid environment. Crop Sciences, 22: 963-970

Naresh, R.K., Rathore, R.S., Yadav, R.B., Singh, S.P., Misra, A.K., Kumar, V., Kumar, N., and Gupta Raj, K. 2014. Effect of precision land levelling and permanent raised bed planting on soil properties, input use efficiency, productivity and profitability under maize (Zea mays)-wheat (Triticum aestivum) cropping system. African Journal of Agricultural Research, 9(36): 2781-2789

Pirayvatlou, A.S. 2001. Relations among yield potential, drought tolerance and stability of yield in bread wheat cultivars under water deficit conditions. Proceedings of the 10th Australian Agronomy Conference, Hobart, January 29, 2001

Rajmani, A.1994. Screening Gossypium hirsutum genotypes for drought tolerance. Madras Agricultural Journal, 81: 465-468

Ramirez, P. and Kelly, J. D. 1998. Traits related to drought resistance in common bean. Euphytica, 99: 127-136

Rosielle, A.A. and Hamblin, J. 1981. Theoretical aspects of selection for yield in stress and non-stress environments. Crop Science, 21: 943-946

Sio-Se Mardeh, A., A. Ahmadi, K. Poustini and V. Mohammadi. 2006. Evaluation of drought resistance indices under various environmental conditions. Field Crop Research, 98: 222-229. 
Sharafi, S., Ghassemi, G.K., Mohammadi, S., Lak, S. and Sorkhy, B. 2011. Evaluation of drought tolerance and yield potential in winter barley (Hordeum vulgare) varieties. Journal of Food Agriculture and Environment, 9: 419-422

Shen, Z., Ren, J., Wang, Z. and Cui, W. 2011. Effects of initial water content and irrigation frequency on soil-water dynamics under subsurface drip irrigation. Journal of Food, Agriculture and Environment, 9: 666-671

Talebi, R., Fayaz, F. and Naji, A.M. 2009. Effective selection criteria for assessing drought stress tolerance in durum wheat (Triticum durum). General and Applied Plant Physiology, 35: 64-74

Zangi, M.R. 1998. Drought resistance evaluation in cotton and path analysis of its effective characters. M.Sc. Thesis, Tarbiat Modares University, Iran

Zangi, M.R. 2005. Correlation Between Drought Resistance Indices and Cotton Yield in Stress and Non Stress Conditions. Asian Journal of Plant Sciences, 4: 106-108 
Table 1. MSS of different indices (Over the year's analysis)

\begin{tabular}{|l|l|l|l|l|l|l|l|l|}
\hline Source of variation & df & Ypi & Ysi & TOL & STI & SSI & MP & GMP \\
\hline Year & 1 & $690.3^{*}$ & $9397.3^{*}$ & $4997.2^{*}$ & $2.1^{*}$ & 0.01 & $3796.8^{*}$ & $5294.4^{*}$ \\
\hline Block & 2 & 9.5 & 1.8 & 3.6 & 0.004 & 0.08 & 4.7 & 5.5 \\
\hline Genotype & 14 & $84.0^{*}$ & $45.1^{*}$ & $36.9^{*}$ & $0.04^{*}$ & 0.07 & $55.4^{*}$ & $52.7^{*}$ \\
\hline Genotype X Year & 14 & 26.2 & $11.9^{*}$ & 31.4 & 0.008 & 0.05 & 11.2 & 11.2 \\
\hline Error & 58 & 29.4 & 3.7 & 26.6 & 0.006 & 0.06 & 9.9 & 8.4 \\
\hline
\end{tabular}

*Significant $(\mathrm{P}=0.05)$

Ypi: Yield under Normal Conditions

Ysi: Yield under Stress Conditions

TOL: Stress Tolerance

STI: Stress Tolerance Index

SSI: Stress Susceptibility Index

MP: Mean Productivity

GMP: Geometric Mean Productivity 
Table 2. Stress tolerance indices in wheat varieties for crop season 2010-11, 2011-12

These indices should be presented in graphical forms separately in result and discussion section

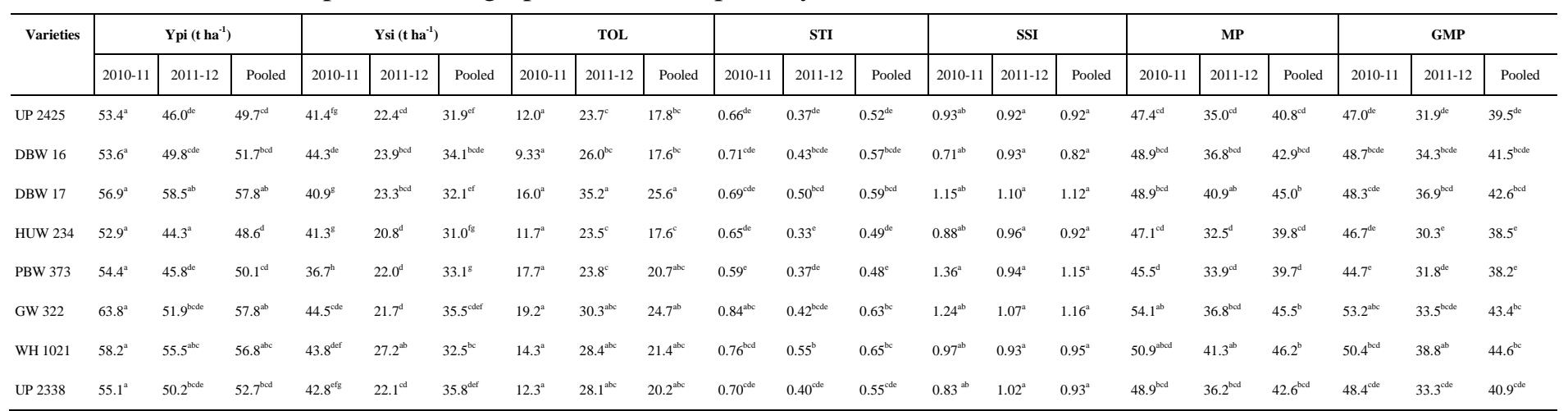

Ypi: Yield under Normal Conditions

Ysi: Yield under Stress Conditions

TOL: Stress Tolerance

STI: Stress Tolerance Index

SSI: Stress Susceptibility Index

MP: Mean Productivity

GMP: Geometric Mean Productivity 
Table 3. Correlation between various stress tolerance parameters

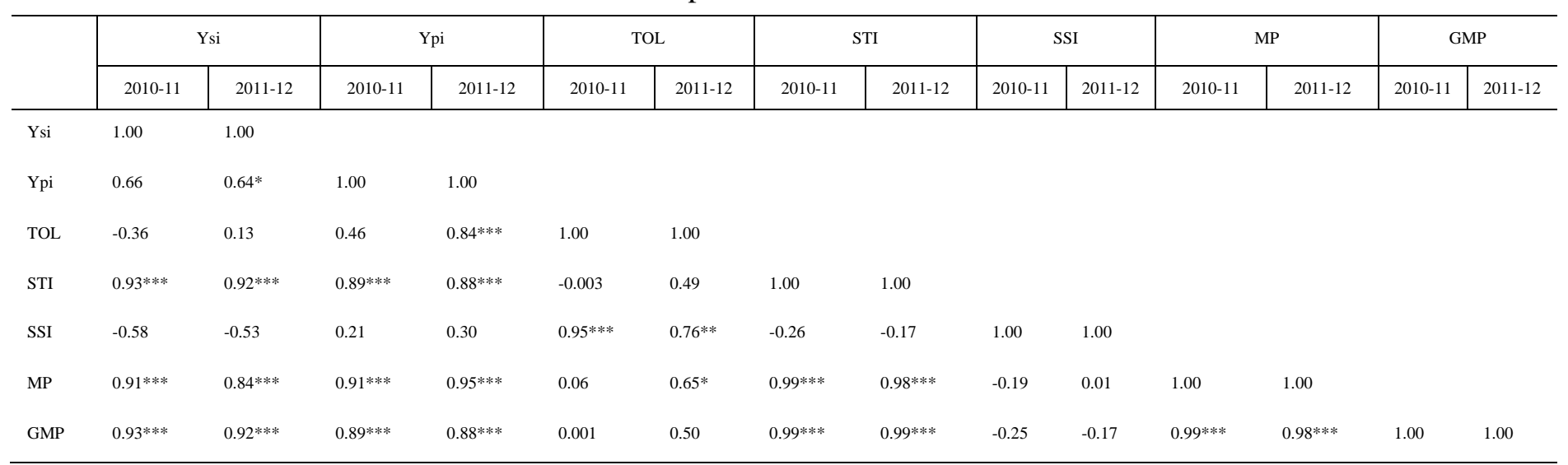

Pearson Correlation Coefficients $\quad *=0.05, * *=0.01, * * *=0.001$ 
Table 4. Effect of moisture stress on tillers $/ \mathrm{m}^{2}$, chlorophyll content at physiological maturity and thousand grain weight of wheat varieties

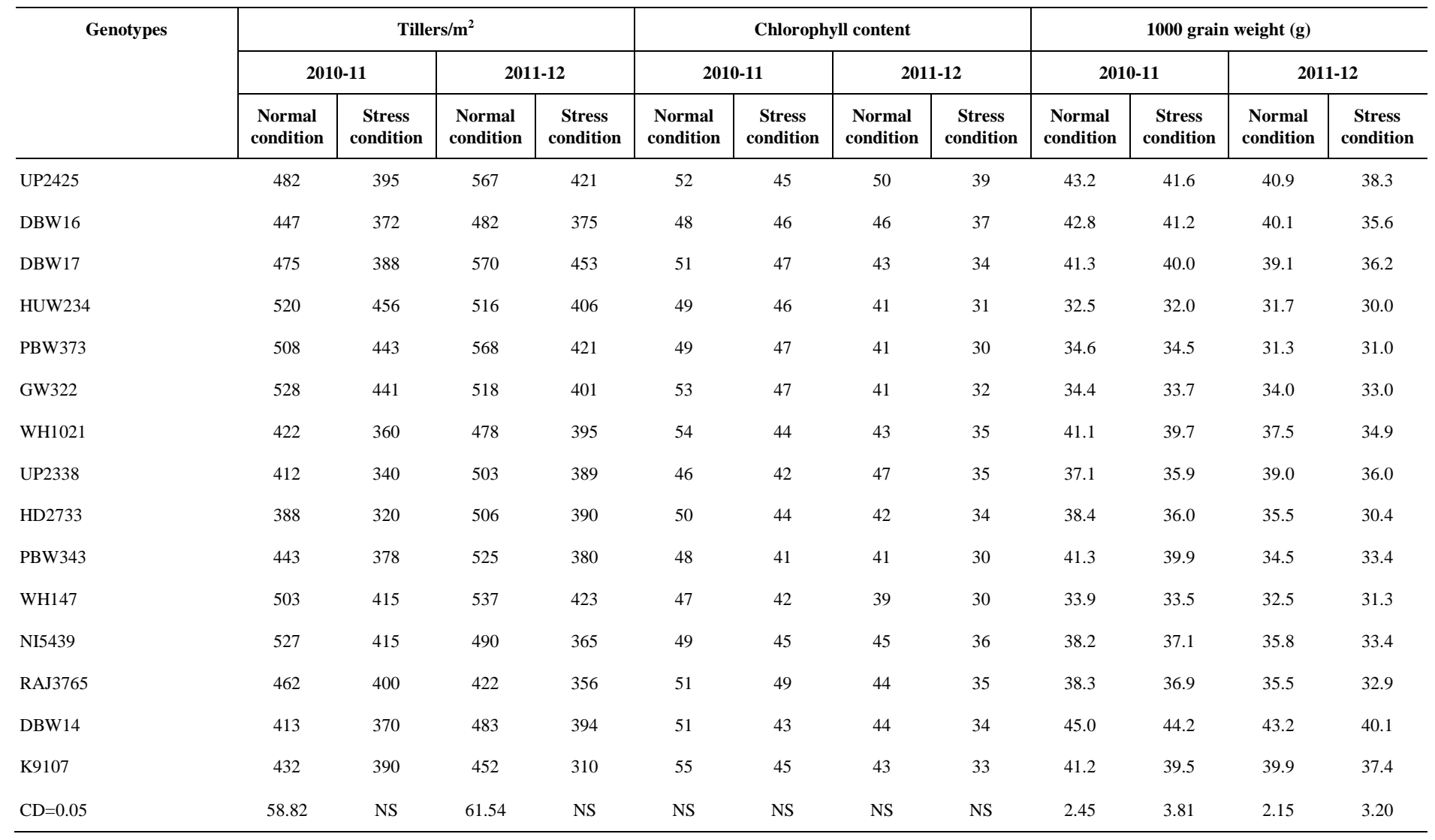

